\title{
Acetaminophen (Paracetamol): Use beyond Pain Management and Dose Variability
}

\author{
Christopher J. Esh ${ }^{1}$, Alexis R. Mauger ${ }^{2}$, Roger A. Palfreeman ${ }^{3}$, Haifa Al-Janubi ${ }^{4}$ and \\ Lee Taylor ${ }^{1,5 *}$ \\ ${ }^{1}$ Aspetar - Qatar Orthopaedic and Sports Medicine Hospital, Athlete Health and Performance Research Centre, Doha, \\ Qatar, ${ }^{2}$ Endurance Research Group, School of Sport and Exercise Sciences, University of Kent, Chatham Maritime, \\ Chatham, United Kingdom, ${ }^{3}$ Aspetar - Qatar Orthopaedic and Sports Medicine Hospital, Exercise and Sports Science \\ Department, Doha, Qatar, ${ }^{4}$ Aspetar - Qatar Orthopaedic and Sports Medicine Hospital, Pharmacy Department, Doha, Qatar, \\ ${ }^{5}$ School of Sport, Exercise and Health Sciences. Loughborough University, Loughborough, United Kingdom
}

Keywords: acetaminophen, cyclooxygenase, prostaglandin E2, antipyretic, analgesic

\section{INTRODUCTION}

Inappropriate prescribing of analgesics or self-administration through over the counter formulations results in regular often negative reporting within the media. Indeed, their abuse within elite through to recreational sport is not uncommon (Feucht and Patel, 2010; Warden, 2010; Tscholl and Dvorak, 2012; Brewer et al., 2014). For example, acetaminophen (ACT; commonly known as paracetamol) use is even prevalent in young sub-elite athletes, who consume ACT or other analgesics [e.g., non-steroidal anti-inflammatory drugs (NSAIDs)] to decrease pain from previous athletic exertion or prophylactically to reduce pain in subsequent training/competition (Garcin et al., 2005). Related recent headlines include a former FIFA Chief Medical Officer stating that "about half of players competing at the past three World Cups routinely took NSAIDs like ibuprofen" whilst former players report pressure to use such drugs "to get through games" (BBCSport, 2017). NSAIDs and ACT are the most commonly used antipyretic and analgesic drugs worldwide (Hinz and Brune, 2012). Given they are available over the counter, their use even with careful club/team physician oversight can be difficult to police within a professional sport environment. If team clinicians ban over the counter analgesia use, players can and do simply self-administer, increasing risk of drug interaction with clinician prescribed medications and/or over-dose risk (inadvertently or otherwise).

ACT has been used globally since 1955 and is considered a safe effective analgesic (Bunchorntavakul and Reddy, 2013). The analgesic properties of ACT are similar to NSAIDs, yet ACT does not share similar NSAID mediated anti-inflammatory actions (Graham et al., 2013). ACT carries fewer, if any, side-effects when used at appropriate dosages compared to NSAIDs (Towheed et al., 2006; Jones et al., 2015). NSAIDs side-effects can include gastrointestinal and arterial wall damage, gastrointestinal ulcers, arterial blood clotting, myocardial infarction, stroke and hemorrhage perforation, amongst others (Ong et al., 2007; Van Wijck et al., 2012). The well evidenced and publicized side-effect of ACT is liver necrosis in cases of acute overdose [e.g., ACT at 250 mg.kg, $15 \mathrm{~g}$ for a $60 \mathrm{~kg}$ human (Prescott et al., 1971; Prescott, 1980; Raffa et al., 2014)], evidently not seen under appropriate acute and/or regular use (Skoglund et al., 1991; Dippel et al., 2003a). Although uncommon relative to ACT chronic use, liver necrosis has been reported when concomitant with other factors such as fasting/malnutrition, alcoholism and the use of cytochrome P450 enzyme inducing drugs (Vitols, 2003).

Novel research has seen ACT used outside of its typical clinical parameters, including exercise performance domains (Mauger et al., 2010, 2014; Foster et al., 2014) and to induce mild 
hypothermia within afebrile humans (Foster et al., 2016, 2017). ACT use whilst safe in many scenarios (Ong et al., 2007; Graham et al., 2013) does present risk in others (Hinz and Brune, 2012; Aminoshariae and Khan, 2015), across research and clinical agendas. This opinion piece will detail the variable acute dose and chronic dosages, and their pharmacological safety across established and emerging research fields. In particular, this article will present evidence to support the following opinions:

(1) ACT should not be advocated for use within a sporting context, given the present evidence is from tightly controlled laboratory studies which do not replicate the multifaceted physiological, biochemical, and environmental perturbations to homeostasis during sporting performance.

(2) ACT may provide a useful tool in determining fundamental biochemical thermoregulatory mechanisms in vivo in humans, when appropriate experimental controls and designs are employed.

\section{EMERGING ACETAMINOPHEN USE WITHIN PHYSIOLOGY RESEARCH}

Evidence presented/discussed herein focuses on orally administered ACT in adult populations (unless stated otherwise). An "acute" ACT dose constitutes one-time single administration, whilst a chronic ACT "dosage" describes multiple doses over a day(s). An adult therapeutic dose of ACT is a $1 \mathrm{~g}$ single dose or a dosage of $4^{*} 1 \mathrm{~g}$ daily at $4-6 \mathrm{~h}$ intervals (Bunchorntavakul and Reddy, 2013). Children aged 2-12 years are normally given an individualized body weight derived therapeutic dose at 10-15 mg.kg (Jackson et al., 1984). ACT has been used beyond its primary functions as an analgesic and antipyretic in attempts to understand or augment athletic performance (Mauger et al., 2010, 2014; Mauger and Hopker, 2012; Foster et al., 2014) and manipulate/characterize thermoregulation within temperate, cold and hot environments (Dippel et al., 2001, 2003b; Coombs et al., 2015; Taylor et al., 2015; Foster et al., 2016, 2017). From these specific fields of research, no evidence of adverse reactions to ACT have been reported. The evidence informed safety of ACT from seminal work across a variety of populations will be discussed later in this article (see ACT dose and pharmacokinetics section).

An acute $\leq 1.5 \mathrm{~g}$ ACT dose has been used in athletic performance research to improve time trial, time to exhaustion and repeated sprint exercise performance (Mauger et al., 2010, 2014; Mauger and Hopker, 2012; Foster et al., 2014). These effects were attributed to ACT-mediated reductions in exercise induced pain, resulting in maintenance of a higher power output and/or an increased time to exhaustion, despite no change in perceived pain or exertion compared to a placebo condition (Mauger et al., 2010, 2014; Foster et al., 2014). Whilst tolerance of exercise induced pain can be crucial to athletic performance (Ayoub et al., 2004; Amann et al., 2009; Astokorki and Mauger, 2017a,b), it also serves to provide essential feedback on injury and/or fatigue [i.e., a deterrent/modulator of an activity potentially causative of harm (Mauger, 2013)]. Indeed, complete inhibition of pain elicited adoption of an over-aggressive sub-optimal cycling pacing strategy resulting in greater peripheral fatigue and no improvement in athletic performance, without injury pesentation (Amann et al., 2009). This suggests that pain may provide valuable feedback to higher centers to maintain an "optimal" distribution of work rate (Ayoub et al., 2004; Astokorki and Mauger, 2017a,b; St Clair Gibson et al., 2017).

Disruption of thermoregulatory mechanisms by ACT have been linked to improved time to exhaustion during cycling exercise in the heat (Mauger et al., 2014). Attributed to core temperature $(\mathrm{Tc})$, skin temperature, body temperature and thermal sensation being significantly reduced in the ACT compared to placebo condition (Mauger et al., 2014). This suggests ACT disrupted thermoregulatory mechanisms and reduced thermal strain during exercise (Mauger et al., 2014), as observed elsewhere (Burtscher et al., 2013; Veltmeijer et al., 2016). These specific thermoregulatory effects of ACT may, or may not, have been complemented by the analgesic effects discussed above (Mauger et al., 2010; Foster et al., 2014). It must be stated here that the above exercise performance discussions are not advocating the use of ACT within these domains. The clinician and athlete (elite or otherwise) together should deliberate the ethical and safety considerations of strategies that override homeostatic controls before implementing them to enhance exercise performance, or indeed for any other purpose (clinically or otherwise).

ACT can alter thermoregulation in clinical (Dippel et al., 2001, 2003b; Koennecke and Leistner, 2001; Kasner et al., 2002) and healthy populations (Foster et al., 2016, 2017). Up to half of patients who suffer an acute stroke present with a febrile Tc (Dippel et al., 2001). ACT administration elicited dose dependent Tc reductions of $0.4^{\circ} \mathrm{C}\left[6^{*} 1 \mathrm{~g} /\right.$ day for 5 days (Dippel et al., 2001, 2003b)] and $0.22^{\circ} \mathrm{C}$ [3.9 g/day for 5 days (Kasner et al., 2002)] in these patients. ACT ingestion [20 mg.kg lean body mass (LBM)] induced mild hypothermia (range: $0.1-0.39^{\circ} \mathrm{C}$ drop in $\mathrm{Tc}$ ) in afebrile participants housed in ambient conditions of $20^{\circ} \mathrm{C} 40 \%$ relative humidity [RH (Foster et al., 2016)]. Such conditions are below the human thermoneutral zone (TNZ) where the body invokes mechanisms to maintain a stable Tc (Stocks et al., 2004). Within a similar design to Foster et al. (2016), Foster et al. (2017) demonstrated within cold $\left(10^{\circ} \mathrm{C} 40 \%\right.$ $\mathrm{RH})$ compared to thermoneutral conditions $\left(25^{\circ} \mathrm{C} 40 \% \mathrm{RH}\right)$, ACT ingestion (20 mg.kg LBM) elicited Tc instability (Foster et al., 2017). Specifically, Tc decreased in the cold condition $\left(10^{\circ} \mathrm{C} 40 \% \mathrm{RH}\right)$ with $\mathrm{ACT}$ ingestion (range: $\left.0.16-0.57^{\circ} \mathrm{C}\right)$ and remained stable within the cold placebo condition whilst Tc stability was maintained in both placebo and ACT thermoneutral conditions $\left(25^{\circ} \mathrm{C} 40 \% \mathrm{RH}\right)$. This in vivo human data suggest ACT has inhibitory actions on heat producing mechanisms in certain febrile (Dippel et al., 2001, 2003b; Koennecke and Leistner, 2001; Kasner et al., 2002) and afebrile states (Foster et al., 2016, 2017). Within afebrile states the limited data suggests hypothermic effects present only below the human TNZ (Foster et al., 2016, 2017).

Mechanistically it appears ACT has an ability to disrupt "normal" thermoregulatory mechanisms in humans beneath the TNZ (Foster et al., 2016, 2017). This is outside ACT's typical use as an analgesic and febrile antipyretic. Indeed, whilst 
explicitly described within rodents (Langenbach et al., 1995; Ayoub et al., 2004), the cyclooxygenase (COX)-prostaglandin E2 (PGE2) thermogenesis pathway (detailed below) has not been robustly determined in vivo within humans. COX1 knockout mice produced 99\% less PGE2 than their wild type counterparts (Langenbach et al., 1995). No compensatory COX2 production to maintain PGE2 levels occurred when inflammation was not present (Langenbach et al., 1995). Such data indicate that PGE2 production, and thus thermogenesis, is somewhat dependent upon COX1 in the absence of a febrile and/or inflammatory state. Confirming the thermogenic influence of this COX1-PGE2 pathway in afebrile and non-inflammatory mammal's, housed beneath their TNZ, is a robust dose dependent drop in Tc within wild type mice [i.e., not COX1 knockout mice (Ayoub et al., 2004; Fukushima et al., 2017)]. ACT administration in the largest doses $(300 \mathrm{mg} . \mathrm{kg})$ produced the greatest Tc decreases [2 and $4^{\circ} \mathrm{C}$ (Ayoub et al., 2004; Fukushima et al., 2017)], and a 96\% reduction in PGE2 concentrations (Ayoub et al., 2004). There is uncertainty within the literature on the function of a third COX isoform within mammals, a splice variant of COX1, COX3. This data suggests that $\mathrm{COX} 3$ could be the primary target of ACT (Botting, 2000; Chandrasekharan et al., 2002; Botting and Ayoub, 2005). These COX1-3 (Chandrasekharan et al., 2002; Botting and Ayoub, 2005) and/or PGE2 (Langenbach et al., 1995; Ayoub et al., 2004) results were generalized to humans without specific evidence (Kis et al., 2005) given the analgesic and antipyretic functions of ACT are closely related to COX2 inhibition (Graham and Scott, 2005; Graham et al., 2013). The human specific general consensus within the literature, is that the inhibition of COX isoforms, COX1 (maintains homeostasis) and COX2 [combats pathophysiological states including inflammation, pain and fever (Fitzpatrick, 2004; Hinz et al., 2008; Rouzer and Marnett, 2009; Hinz and Brune, 2012; Graham et al., 2013; JózwiakBebenista and Nowak, 2013)] alter "normal" thermoregulatory physiological responses/controls. Yet this consensus is derived from rodents, albeit robustly (Langenbach et al., 1995; Ayoub et al., 2004), and not substantiated in vivo in humans. Research to confirm such consensus in humans is paramount given the wide variance of responses to ACT observed between and even within species (different strains) of laboratory animals (Bessems and Vermeulen, 2001). In light of the evidence from Foster et al. (2016), Foster et al. (2017) and related hypotheses (Foster et al., 2015) future well-controlled experimental trials, in vivo in humans, utilizing ACT to inhibit COX could characterize COX13 and PGE2 concentrations and their mechanistic relationship with thermogenesis.

Given the increasing prevalence of research conducted using ACT outside of its typical functions (Mauger et al., 2010, 2014; Mauger and Hopker, 2012; Foster et al., 2014, 2016, 2017; Coombs et al., 2015) the matter of pharmacological safety is current, relevant and important. A plethora of evidence is available highlighting the safety of ACT, including doses/dosages beyond (e.g., $20 \mathrm{mg} . \mathrm{kg}$, $20 \mathrm{mg} . \mathrm{kg} \mathrm{LBM}$, up to $2 \mathrm{~g}$ ) the typical therapeutic range described earlier. Despite this, ACT often receives seemingly unwarranted negative exposure. This is likely due to a high incident rate of acute liver failure in cases of overdose, which accounts for $50 \%$ of all acute liver failure cases in the United States (Bunchorntavakul and Reddy, 2013; Yoon et al., 2016). In these ACT acute liver failure cases, treatment with ACT antidote $\mathrm{N}$-acetyl cysteine produces low estimated mortality rates of $0.4 \%$ (Bunchorntavakul and Reddy, 2013; Yoon et al., 2016). Without rapid treatment of an overdose the risk of acute liver failure and death rises significantly (Blieden et al., 2014). The minimum acute ACT dose observed to induce acute liver failure is $125 \mathrm{mg} . \mathrm{kg}$ body mass (Prescott, 1983). However, incidents are more commonly observed when doses exceed $250 \mathrm{mg} . \mathrm{kg}$ body mass [equivalent to $15 \mathrm{~g}$ for a $60 \mathrm{~kg}$ human (Prescott, 1983)], far greater than that utilized in recent novel applied research [20 mg.kg LBM up to $1.5 \mathrm{~g}$ (Mauger et al., 2010, 2014; Mauger and Hopker, 2012; Foster et al., 2014, 2016, 2017; Coombs et al., 2015; Taylor et al., 2015)]. From chronic use of ACT however, there are several incidents of hepatotoxicity from chronic therapeutic doses but these cases are concomitant with other drug use, periods of starvation, other illnesses and apparent allergic reactions (Vitols, 2003). When proposed for use within a research context and the dose exceeds what is typically considered therapeutic ( $1 \mathrm{~g})$, ACT is often treated with non-evidenceinformed scrutiny by ethical review boards. The next section of this article seeks to summarize existing literature and provide evidence of safe ACT doses/dosages, their pharmacokinetics and highlight the minimal risk ACT poses to health within research, when evidence informed dose/dosages are utilized.

\section{ACETAMINOPHEN DOSE AND PHARMACOKINETICS}

High rates of overdose incidents are likely due to the ease of access to ACT over the counter, (Bunchorntavakul and Reddy, 2013; Yoon et al., 2016). Taken orally ACT is rapidly metabolized in the gastrointestinal tract and then primarily by the liver into toxic and non-toxic compounds (Hodgman and Garrard, 2012). Absorption through the gastric mucosa is negligible but rapid from the small intestine and thus the rate of absorption is determined by the rate of gastric emptying (Prescott, 1980). Whilst gastric emptying can be slowed by food intake the total amount of ACT absorbed over time would not be affected (Prescott, 1980). The volume of distribution once in general circulation, in healthy adults, is circa 501 (Forrest et al., 1982). Seminal and emerging research provides substantial evidence that ACT, even administered above the therapeutic dose $(1 \mathrm{~g})$, is safe. Within healthy, and some clinical populations, doses/dosages up to $2 \mathrm{~g}$ acutely and $2 \mathrm{~g} 4$ * daily over multiple days have been used within research (Forrest et al., 1979; Benson, 1983; Skoglund and Pettersen, 1991; Skoglund et al., 1991; Dippel et al., 2001, 2003b). The plasma half-life of acute therapeutic (1 g) and larger doses of ACT ( $20 \mathrm{mg} . \mathrm{kg}$ up to $1.5 \mathrm{~g}$ ) ranges between 1.5 and $4 \mathrm{~h}$ in humans, with $95 \%$ of the dose excreted via urination $24 \mathrm{~h}$ post ingestion as unchanged ACT or conjugated with glucuronic acid, sulphuric acid, mercapturic acid and cysteine (Prescott et al., 1971; Forrest et al., 1979, 1982; Prescott, 1980). Only in those with clinical liver damage is ACT plasma halflife prolonged up to and in excess of $4 \mathrm{~h}$ (Prescott et al., 1971; Forrest et al., 1979). Typically within clinical trials the zenith in 
plasma concentrations reach $10-25 \mu \mathrm{g} / \mathrm{ml} 1-2 \mathrm{~h}$ post ingestion (Slattery et al., 1987; Singla et al., 2012). A well-controlled pharmacokinetic study in healthy individuals saw peak plasma concentrations of $8-19 \mu \mathrm{g} / \mathrm{ml}$ from an individualized dose (20 mg.kg LBM) up to $\sim 1.5 \mathrm{~g}$ (range: $1.019-1.42 \mathrm{~g}$ ), reached within $120 \mathrm{~min}$ of oral ingestion (Foster et al., 2016). If peak plasma concentrations exceed $300 \mu \mathrm{g} / \mathrm{ml}$ liver damage is likely (Prescott, 1983). If plasma concentrations of $200 \mu \mathrm{g} / \mathrm{ml} 4 \mathrm{~h}$ post ingestion are seen the risk of developing hepatotoxicity significantly increases (Bunchorntavakul and Reddy, 2013). To contextualize, acute therapeutic doses (1 $\mathrm{g}$ ) or those slightly larger $(20 \mathrm{mg} . \mathrm{kg}$ up to $1.5 \mathrm{~g}$ ) produce plasma concentrations of 8-25 $\mu \mathrm{g} / \mathrm{ml}$ (Rawlins et al., 1977; Slattery et al., 1987; Singer et al., 1995; Foster et al., 2016). This is some $175 \mu \mathrm{g} / \mathrm{ml}$ lower than that typically associated with a risk of hepatotoxicity (Bunchorntavakul and Reddy, 2013) and $275 \mu \mathrm{g} / \mathrm{ml}$ lower than the established thresholds for liver damage (Prescott, 1983). Liver damage in response to therapeutic ACT doses have only been seen in very specific populations-those who are alcohol dependent, patients receiving enzyme-inducing drugs and those with specific infectious diseases such as measles and infectious mononucleosis (Collins and Starmer, 1995; Zimmerman and Maddrey, 1995; Prescott, 2000; Aminoshariae and Khan, 2015). Indeed, doses in the range of $1-1.5 \mathrm{~g}$ (when a $20 \mathrm{mg} . \mathrm{kg} \mathrm{LBM}$ dose is employed) in exercise performance research (Mauger et al., 2010, 2014; Mauger and Hopker, 2012; Foster et al., 2014) and 20 mg.kg LBM (up to a maximum of $1.5 \mathrm{~g}$ ) in thermophysiology literature (Foster et al., 2016, 2017) have been used, without reported side-effects; not unexpected given the previous comments regarding plasma ACT concentrations and liver damage. Indeed, $2 \mathrm{~g}$ acute doses (even when repeated within-day) have been tolerated without liver-related or any other side-effects (Skoglund and Pettersen, 1991). Despite this, ACT receives negative reactions when proposed for use within a research context regarding acute doses outside a range that is typically considered therapeutic $(1 \mathrm{~g})$. Even with evidence suggesting these are entirely safe (e.g., 20 mg.kg, 20 mg.kg LBM, or $1.5 \mathrm{~g}$ ) provided they are not administered to the clinical populations outlined above and the fact that such doses have already been utilized regularly elsewhere (Skoglund et al., 1991; Dippel et al., 2001, 2003b; Mauger et al., 2010, 2014; Foster et al., 2014, 2016, 2017).

Whilst no side-effects were reported from acute $2 \mathrm{~g}$ (Skoglund and Pettersen, 1991) and $20 \mathrm{mg} . \mathrm{kg}$ LBM (up to $1.5 \mathrm{~g}$ maximum) ACT administration (Foster et al., 2014, 2016; Mauger et al., 2014; Coombs et al., 2015), gastrointestinal damage or liver necrosis were not quantitatively assessed. However, Benson (1983), Dippel et al. (2001), Dippel et al. (2003b) and Forrest et al. (1979) who implemented a range of liver function tests (aspartate aminotransferase, alanine aminotransferase, alkaline phosphatase and total bilirubin levels) demonstrated no liver-related side-effects using similar doses. Chronic dosages exceeding the therapeutic dose $\left(6^{*} 1 \mathrm{~g}\right.$ /day) over five days in acute ischemic stroke patients (Dippel et al., 2001, 2003b) saw six adverse liver events in the ACT and ibuprofen condition and three in the placebo condition (Dippel et al., 2003b). Overall adverse events (gastrointestinal damage, pneumonia, progressive stroke) were seen equally across ACT, ibuprofen and placebo condition (Dippel et al., 2001, 2003b) and therefore could not be fully attributed to the treatment with ACT. Furthermore, it must be emphasized that this data (Dippel et al., 2001, 2003b) is from a population presenting with pathophysiology (i.e., acute ischemic stroke) that increases the biomarkers typically associated with the diagnosis of liver related "adverse events." For example, an increase in direct bilirubin is correlated with the severity of stroke (Pineda et al., 2008; Luo et al., 2012; Muscari et al., 2014). Indeed, even within patients with stable, mild and severe chronic liver disease, ACT administration (1.5 g acute, $4{ }^{*} 1$ g/day for 5 and 14 days) has not been shown to exacerbate liver damage (Forrest et al., 1979; Benson, 1983). Rather prolongation of the ACT half-life is seen (Forrest et al., 1979; Benson, 1983), which if not accounted for could lead to accumulative plasma concentrations of ACT beyond thresholds typically considered "safe" [(e.g., $200 \mu \mathrm{g} / \mathrm{ml}$ (Bunchorntavakul and Reddy, 2013)] resulting in inadvertent overdose and thus further liver damage.

From the evidence presented here the standard therapeutic dose of ACT ( $1 \mathrm{~g}$ single dose up to $4 \mathrm{~g}$ daily every $4-6 \mathrm{~h}$ ) has not been reported to induce liver damage (Benson, 1983). Acute doses up to $1.5 \mathrm{~g}$ and dosages up to $6 \mathrm{~g}$ /day have been shown to be safe within clinical (Forrest et al., 1979; Dippel et al., 2001, 2003b) and healthy athletic populations (Foster et al., 2014, 2016, 2017). Evidently with such an excellent safety record these dose/dosages should not be considered a significant risk in research studies. However, various control/safety measures have been employed or could be recommended to provide further reassurance of these albeit small risks for research participants. These could include: (1) utilization of alcohol use disorder identification test (AUDIT; as part of participant inclusion criteria for enrolment onto a research project); (2) breathalyzer use (prior to ACT ingestion); (3) the satisfactory completion of an ACT risk assessment questionnaire (Foster et al., 2016, 2017). Following these processes if the researcher or participant are unsure of their suitability then medical clearance can be sought. These recommendations could act to reduce the already minimal risk of ACT-mediated side-effects in apparently healthy populations. Their adoption within germane ACT centric research designs should appease any ethically orientated and/or participant safety concerns. Indeed, such measures have seen use elsewhere already (Foster et al., 2016, 2017).

\section{SUMMARY AND CONCLUSIONS}

From the evidence presented here ACT does not pose a major threat to health, particularly compared to the adverse events seen with NSAID use, unless taken in inappropriate dose/dosages and/or by certain clinical populations. Experimental controls have been suggested to reduce the already low side-effect risk from ACT administration within relevant human experimental designs. While there is evidence of ACT being beneficial during exercise, this is within a well-controlled research setting where interactions with other medication and supplements (NSAIDs, caffeine, etc.), other common conditions (redistribution of blood flow, hydration status, diet, etc.) and the intensity of exercise 
are explicitly controlled to ensure the safety of participants. ACT use during exercise where such robust controls are not in place must not be advocated, the risk of interaction with any of the stated factors is not known and may increase the danger of injury/damage to an individual. ACT may be a useful tool to explore and validate bio-chemical thermophysiological mechanisms within afebrile human populations. ACT may alter heat producing mechanisms via inhibition of COX and subsequently PGE2, which requires evidence in vivo from humans in lieu of rodent evidence discussed above. Drugs that have COX inhibiting mechanisms, are associated with potentially severe adverse side-effects (Ong et al., 2007) although, ACT has been shown to have a favorable risk profile compared to other common COX inhibiting drugs such as NSAIDs, particularly relative to gut damage (Towheed et al., 2006; Jones et al., 2015). Given the propensity of exercise stress to induce endotoxemia, intestinal hypoperfusion, and intestinal cellular injury/damage (van Wijck et al., 2011; ter Steege et al., 2012; March et al., 2017), a result of redistribution of blood flow during exercise compromising the intestinal mucosa wall (Van Wijck et al., 2012; Yeh et al., 2013), such damage could be incurred if ACT was to be used during uncontrolled exercise (i.e., outside of research) within any environment (although

\section{REFERENCES}

Amann, M., Proctor, L. T., Sebranek, J. J., Pegelow, D. F., and Dempsey, J. A. (2009). Opioid-mediated muscle afferents inhibit central motor drive and limit peripheral muscle fatigue development in humans. J. Physiol. 587, 271-283. doi: 10.1113/jphysiol.2008.163303

Aminoshariae, A., and Khan, A. (2015). Acetaminophen: old drug, new issues. J. Endod. 41, 588-593. doi: 10.1016/j.joen.2015.01.024

Astokorki, A. H., and Mauger, A. R. (2017b). Transcutaneous electrical nerve stimulation reduces exercise-induced perceived pain and improves endurance exercise performance. Eur. J. Appl. Physiol. 117, 483-492. doi: 10.1007/s00421-016-3532-6

Astokorki, A., and Mauger, A. R. (2017a). Tolerance of exercise-induced pain at a fixed rating of perceived exertion predicts time trial cycling performance. Scand. J. Med. Sci. Sports 27, 309-317. doi: 10.1111/sms.12659

Ayoub, S. S., Botting, R. M., Goorha, S., Colville-Nash, P. R., Willoughby, D. A., and Ballou, L. R. (2004). Acetaminophen-induced hypothermia in mice is mediated by a prostaglandin endoperoxide synthase 1 gene-derived protein. Proc. Natl. Acad. Sci. U.S.A. 101, 11165-11169. doi: 10.1073/pnas.0404185101

BBCSport (2017). State Of Sport: Fifa's Former Doctor Says Painkiller Use Risks Footballers' Health. BBC Sport. Available Online at: http://www.bbc.com/sport/ 39333763 (Accessed April 12, 2017).

Benson, G. D. (1983). Acetaminophen in chronic liver-disease. Clin. Pharmacol. Ther. 33, 95-101. doi: 10.1038/clpt.1983.14

Bessems, J. G., and Vermeulen, N. P. (2001). Paracetamol (acetaminophen)induced toxicity: molecular and biochemical mechanisms, analogues and protective approaches. Crit. Rev. Toxicol. 31, 55-138. doi: 10.1080/20014091111677

Blieden, M., Paramore, L. C., Shah, D., and Ben-Joseph, R. (2014). A perspective on the epidemiology of acetaminophen exposure and toxicity in the United States. Expert Rev. Clin. Pharmacol. 7, 341-348. doi: 10.1586/17512433.2014.904744

Botting, R., and Ayoub, S. S. (2005). COX-3 and the mechanism of action of paracetamol/acetaminophen. Prostaglandins Leukot. Essent. Fatty Acids 72, 85-87. doi: 10.1016/j.plefa.2004.10.005

Botting, R. M. (2000). Mechanism of action of acetaminophen: is there a cyclooxygenase 3? Clin. Infect. Dis. 31(Suppl. 5), S202-S210. doi: $10.1086 / 317520$ most likely a hot environment). However, no reports of any adverse effects have occurred thus far in the literature (Mauger et al., 2014; Coombs et al., 2015). Therefore, the potential for ACT to cause any intestinal injury must be established within experimental designs that explore ACT mechanisms during exercise and/or challenging thermal environments. The evidence discussed above rationalizes the following two opinions:

(1) ACT should not be advocated for use within a sporting context, given the present evidence is from tightly controlled laboratory studies which do not replicate the multifaceted physiological, biochemical and environmental perturbations to homeostasis during sporting performance.

(2) ACT may provide a useful tool in determining fundamental biochemical thermoregulatory mechanisms in vivo in humans, when appropriate experimental controls and designs are employed.

\section{AUTHOR CONTRIBUTIONS}

All authors listed have made a substantial, direct and intellectual contribution to the work, and approved it for publication.

Brewer, C. B., Bentley, J. P., Hallam, J. S., Woodyard, C. D., and Waddell, D. E. (2014). Use of analgesics for exercise-associated pain: prevalence and predictors of use in recreationally trained college-aged students. J. Strength Cond. Res. 28, 74-81. doi: 10.1519/JSC.0b013e318291ba98

Bunchorntavakul, C., and Reddy, K. R. (2013). Acetaminophen-related hepatotoxicity. Clin. Liver Dis. 17, 587-607. doi: 10.1016/j.cld.2013. 07.005

Burtscher, M., Gatterer, H., Philippe, M., Krüsmann, P., Kernbeiss, S., Frontull, V., et al. (2013). Effects of a single low-dose acetaminophen on body temperature and running performance in the heat: a pilot project. Int. J. Physiol. Pathophysiol. Pharmacol. 5, 190-193.

Chandrasekharan, N. V., Dai, H., Roos, K. L. T., Evanson, N. K., Tomsik, J., Elton, T. S., et al. (2002). COX-3, a cyclooxygenase-1 variant inhibited by acetaminophen and other analgesic/antipyretic drugs: cloning, structure, and expression. Proc. Natl. Acad. Sci. U.S.A. 99, 13926-13931. doi: 10.1073/pnas.162468699

Collins, C., and Starmer, G. A. (1995). A review of the hepatotoxicity of paracetamol at therapeutic or near-therapeutic dose levels, with particular reference to alcohol abusers. Drug Alcohol Rev. 14, 63-79. doi: 10.1080/09595239500185071

Coombs, G. B., Cramer, M. N., Ravanelli, N. M., Morris, N. B., and Jay, O. (2015). Acute acetaminophen ingestion does not alter core temperature or sweating during exercise in hot-humid conditions. Scand. J. Med. Sci. Sports 25, 96-103. doi: $10.1111 /$ sms.12336

Dippel, D., Van Breda, E., Van Der Worp, H., van Gemert, H., Kappelle, L., Algra, A., et al. (2003a). Timing of the effect of acetaminophen on body temperature in patients with acute ischemic stroke. Neurology 61, 677-679. doi: 10.1212/01.WNL.0000080364.40229.0B

Dippel, D. W. J., van Breda, E. J., van Gemert, H. M. A., van der Worp, H. B., Meijer, R. J., Kappelle, L. J., et al. (2001). Effect of paracetamol (Acetaminophen) on body temperature in acute ischemic stroke. A double-blind, randomized phase II clinical trial. Stroke 32, 1607-1612.

Dippel, D. W., Van Breda, E. J., van der Worp, H. B., van Gemert, H. M. A., Meijer, R. J., Kappelle, L. J., et al. (2003b). Effect of paracetamol (acetaminophen) and ibuprofen on body temperature in acute ischemic stroke PISA, a phase II double-blind, randomized, placebo-controlled trial [ISRCTN98608690]. BMC Cardiovasc. Disord. 3:2. doi: 10.1186/1471-2261-3-2 
Feucht, C. L., and Patel, D. R. (2010). Analgesics and anti-inflammatory medications in sports: use and abuse. Pediatr. Clin. North Am. 57, 751-774. doi: $10.1016 /$ j.pcl.2010.02.004

Fitzpatrick, F. A. (2004). Cyclooxygenase enzymes: regulation and function. Curr. Pharm. Des. 10, 577-588. doi: 10.2174/1381612043453144

Forrest, J. A., Adriaenssens, P., Finlayson, N. D., and Prescott, L. F. (1979). Paracetamol metabolism in chronic liver-disease. Eur. J. Clin. Pharmacol. 15, 427-431. doi: 10.1007/BF00561743

Forrest, J. A., Clements, J. A., and Prescott, L. F. (1982). Clinical pharmacokinetics of paracetamol. Clin. Pharmacokinet. 7, 93-107. doi: 10.2165/00003088-198207020-00001

Foster, J., Mauger, A. R., Chrismas, B. C., Thomasson, K., and Taylor, L. (2015). Is prostaglandin E 2 (PGE 2) involved in the thermogenic response to environmental cooling in healthy humans? Med. Hypotheses 85, 607-611. doi: 10.1016/j.mehy.2015.07.022

Foster, J., Mauger, A. R., Govus, A., Hewson, D., and Taylor, L. (2017). Acetaminophen (paracetamol) induces hypothermia during acute cold stress. Clin. Drug Investig. 37, 1055-1065. doi: 10.1007/s40261-017-0560-x

Foster, J., Mauger, A., Thomasson, K., White, S., and Taylor, L. (2016). Effect of acetaminophen ingestion on thermoregulation of normothermic, non-febrile humans. Front. Pharmacol. 7:54. doi: 10.3389/fphar.2016.00054

Foster, J., Taylor, L., Chrismas, B. C. R., Watkins, S. L., and Mauger, A. R. (2014). The influence of acetaminophen on repeated sprint cycling performance. Eur. J. Appl. Physiol. 114, 41-48. doi: 10.1007/s00421-013-2746-0

Fukushima, A., Sekiguchi, W., Mamada, K., Tohma, Y., and Ono, H. (2017). Serotonergic system does not contribute to the hypothermic action of acetaminophen. Biol. Pharm. Bull. 40, 227-233. doi: 10.1248/bpb.b16-00728

Garcin, M., Mille-Hamard, L., Billat, V., and Imbenotte, M. (2005). Use of acetaminophen in young subelite athletes. J. Sports Med. Phys. Fitness 45:604.

Graham, G. G., Davies, M. J., Day, R. O., Mohamudally, A., and Scott, K. F. (2013). The modern pharmacology of paracetamol: therapeutic actions, mechanism of action, metabolism, toxicity and recent pharmacological findings. Inflammopharmacology 21, 201-232. doi: 10.1007/s10787-013-0172-x

Graham, G. G., and Scott, K. F. (2005). Mechanism of action of paracetamol. Am. J. Ther. 12, 46-55. doi: 10.1097/00045391-200501000-00008

Hinz, B., and Brune, K. (2012). Paracetamol and cyclooxygenase inhibition: is there a cause for concern? Ann. Rheum. Dis. 71, 20-25. doi: 10.1136/ard.2011.200087

Hinz, B., Cheremina, O., and Brune, K. (2008). Acetaminophen (paracetamol) is a selective cyclooxygenase-2 inhibitor in man. FASEB J. 22, 383-390. doi: 10.1096/fj.07-8506com

Hodgman, M. J., and Garrard, A. R. (2012). A review of acetaminophen poisoning. Crit. Care Clin. 28, 499-516. doi: 10.1016/j.ccc.2012.07.006

Jackson, C. H., MacDonald, N. C., and Cornett, J. (1984). Acetaminophen: a practical pharmacologic overview. Can. Med. Assoc. J. 131, 25-32.

Jones, P., Dalziel, S. R., Lamdin, R., Miles-Chan, J. L., and Frampton, C. (2015). Oral non-steroidal anti-inflammatory drugs versus other oral analgesic agents for acute soft tissue injury. Cochrane Database Syst Rev. Cd007789. doi: 10.1002/14651858.CD007789.pub2

Józwiak-Bebenista, M., and Nowak, J. Z. (2013). Paracetamol: mechanism of action, applications and safety concern. Acta Pol. Pharm. 71, 11-23.

Kasner, S. E., Wein, T., Piriyawat, P., Villar-Cordova, C. E., Chalela, J. A., Krieger, D. W., et al. (2002). Acetaminophen for altering body temperature in acute stroke. Stroke 33, 130-135. doi: 10.1161/hs0102.101477

Kis, B., Snipes, J. A., and Busija, D. W. (2005). Acetaminophen and the cyclooxygenase-3 puzzle: sorting out facts, fictions, and uncertainties. J. Pharmacol. Exp. Ther. 315, 1-7. doi: 10.1124/jpet.105.085431

Koennecke, H. C., and Leistner, S. (2001). Prophylactic antipyretic treatment with acetaminophen in acute ischemic stroke: a pilot study. Neurology 57, 2301-2303. doi: 10.1212/WNL.57.12.2301

Langenbach, R., Morham, S. G., Tiano, H. F., Loftin, C. D., Ghanayem, B. I., Chulada, P. C., et al. (1995). Prostaglandin synthase 1 gene disruption in mice reduces arachidonic acid-induced inflammation and indomethacin-induced gastric ulceration. Cell 83, 483-492. doi: 10.1016/0092-8674(95)90126-4

Luo, Y., Li, J.-W., Lu, Z.-J., Wang, C., Guan, D.-N., and Xu, Y. (2012). Serum bilirubin after acute ischemic stroke is associated with stroke severity. Curr. Neurovasc. Res. 9, 128-132. doi: 10.2174/156720212800410876

March, D. S., Marchbank, T., Playford, R. J., Jones, A. W., Thatcher, R., and Davison, G. (2017). Intestinal fatty acid-binding protein and gut permeability responses to exercise. Eur. J. Appl. Physiol. 117, 931-941. doi: 10.1007/s00421-017-3582-4

Mauger, A. R. (2013). Fatigue is a pain-the use of novel neurophysiological techniques to understand the fatigue-pain relationship. Front. Physiol. 4:104. doi: 10.3389/fphys.2013.00104

Mauger, A. R., and Hopker, J. G. (2012). The effect of acetaminophen ingestion on cortico-spinal excitability. Can. J. Physiol. Pharmacol. 91, 187-189. doi: 10.1139/cjpp-2012-0213

Mauger, A. R., Jones, A. M., and Williams, C. A. (2010). Influence of acetaminophen on performance during time trial cycling. J. Appl. Physiol. 108, 98-104. doi: 10.1152/japplphysiol.00761.2009

Mauger, A. R., Taylor, L., Harding, C., Wright, B., Foster, J., and Castle, P. C. (2014). Acute acetaminophen (paracetamol) ingestion improves time to exhaustion during exercise in the heat. Exp. Physiol. 99, 164-171. doi: 10.1113/expphysiol.2013.075275

Muscari, A., Collini, A., Fabbri, E., Giovagnoli, M., Napoli, C., Rossi, V., et al. (2014). Changes of liver enzymes and bilirubin during ischemic stroke: mechanisms and possible significance. BMC Neurol. 14:122. doi: 10.1186/1471-2377-14-122

Ong, C., Lirk, P., Tan, C., and Seymour, R. (2007). An evidence-based update on nonsteroidal anti-inflammatory drugs. Clin. Med. Res. 5, 19-34. doi: $10.3121 / \mathrm{cmr} .2007 .698$

Pineda, S., Bang, O. Y., Saver, J. L., Starkman, S., Yun, S. W., Liebeskind, D. S., et al. (2008). Association of serum bilirubin with ischemic stroke outcomes. J. Stroke Cerebrovasc. Dis. 17, 147-152. doi: 10.1016/j.jstrokecerebrovasdis.2008. 01.009

Prescott, L. (1980). Kinetics and metabolism of paracetamol and phenacetin. Br. J. Clin. Pharmacol. 10(Suppl. 2), 291S-298S. doi: 10.1111/j.1365-2125.1980.tb01812.x

Prescott, L. (1983). Paracetamol overdosage. Drugs 25, 290-314. doi: 10.2165/00003495-198325030-00002

Prescott, L. F. (2000). Paracetamol, alcohol and the liver. Br. J. Clin. Pharmacol. 49, 291-301. doi: 10.1046/j.1365-2125.2000.00167.x

Prescott, L. F., Roscoe, P., Wright, N., and Brown, S. S. (1971). Plasma-paracetamol half-life and hepatic necrosis in patients with paracetamol overdosage. Lancet 297, 519-522. doi: 10.1016/S0140-6736(71)91125-1

Raffa, R. B., Pergolizzi, J. V., Taylor, R., Decker, J. F., and Patrick, J. T. (2014). Acetaminophen (paracetamol) oral absorption and clinical influences. Pain Pract. 14, 668-677. doi: 10.1111/papr.12130

Rawlins, M. D., Henderson, D. B., and Hijab, A. R. (1977). Pharmacokinetics of paracetamol (acetaminophen) after intravenous and oral administration. Eur J. Clin. Pharmacol. 11, 283-286. doi: 10.1007/BF00607678

Rouzer, C. A., and Marnett, L. J. (2009). Cyclooxygenases: structural and functional insights. J. Lipid Res. 50, S29-S34. doi: 10.1194/jlr.R800042-JLR200

Singer, A. J., Carracio, T. R., and Mofenson, H. C. (1995). The temporal profile of increased transaminase levels in patients with acetaminophen-induced liver dysfunction. Ann. Emerg. Med. 26, 49-53. doi: 10.1016/S0196-0644(95) 70237-7

Singla, N. K., Parulan, C., Samson, R., Hutchinson, J., Bushnell, R., Beja, E. G., et al. (2012). Plasma and cerebrospinal fluid pharmacokinetic parameters after single-dose administration of intravenous, oral, or rectal acetaminophen. Pain Pract. 12, 523-532. doi: 10.1111/j.1533-2500.2012.00556.x

Skoglund, L. A., and Pettersen, N. (1991). Effects of acetaminophen after bilateral oral surgery: double dose twice daily versus standard dose four times daily. Pharmacotherapy 11, 370-375.

Skoglund, L. A., Skjelbred, P., and Fyllingen, G. (1991). Analgesic efficacy of acetaminophen $1000 \mathrm{mg}$, acetaminophen $2000 \mathrm{mg}$, and the combination of acetaminophen $1000 \mathrm{mg}$ and codeine phosphate $60 \mathrm{mg}$ versus placebo in acute postoperative pain. Pharmacotherapy 11, 364-369.

Slattery, J. T., Wilson, J. M., Kalhorn, T. F., and Nelson, S. D. (1987). Dose-dependent pharmacokinetics of acetaminophen: evidence of glutathione depletion in humans. Clin. Pharmacol. Ther. 41, 413-418. doi: $10.1038 / \mathrm{clpt} .1987 .50$

St Clair Gibson, A., Swart, J., and Tucker, R. (2017). The interaction of psychological and physiological homeostatic drives and role of general control principles in the regulation of physiological systems, exercise and the fatigue process-The Integrative Governor theory. Eur. J. Sport Sci. doi: 10.1080/17461391.2017.1321688. [Epub ahead of print] 
Stocks, J. M., Taylor, N. A., Tipton, M. J., and Greenleaf, J. E. (2004). Human physiological responses to cold exposure. Aviat. Space Environ. Med. 75, 444-457.

Taylor, L., Chrismas, B., Mauger, A., Thomasson, K., White, S., and Foster, J. (2015). Paracetamol (acetaminophen) ingestion and core body temperature within normothermic and hot conditions at rest. Med. Sci. Sports Exerc. 47:492. doi: 10.1249/01.mss.0000477783.29645.5d

ter Steege, R. W., Geelkerken, R. H., Huisman, A. B., and Kolkman, J. J. (2012). Abdominal symptoms during physical exercise and the role of gastrointestinal ischaemia: a study in 12 symptomatic athletes. Br. J. Sports Med. 46, 931-935. doi: 10.1136/bjsports-2011-090277

Towheed, T., Maxwell, L., Judd, M., Catton, M., Hochberg, M. C., and Wells, G. A. (2006). Acetaminophen for osteoarthritis. Cochrane Database Syst. Rev. CD004257. doi: 10.1002/14651858.CD004257.pub2

Tscholl, P. M., and Dvorak, J. (2012). Abuse of medication during international football competition in 2010-lesson not learned. Br. J. Sports Med. 46, 1140-1141. doi: 10.1136/bjsports-2011-090806

Van Wijck, K., Lenaerts, K., Van Bijnen, A. A., Boonen, B., Van Loon, L., Dejong, C., et al. (2012). Aggravation of exercise-induced intestinal injury by Ibuprofen in athletes. Med. Sci. Sports Exerc. 44, 2257-2262. doi: 10.1249/MSS.0b013e318265dd3d

van Wijck, K., Lenaerts, K., van Loon, L. J. C., Peters, W. H. M., Buurman, W. A., and Dejong, C. H. C. (2011). Exercise-induced splanchnic hypoperfusion results in gut dysfunction in healthy men. PLoS ONE 6: e22366. doi: 10.1371/journal.pone.0022366

Veltmeijer, M. T., Veeneman, D., Bongers, C. C., Netea, M. G., van der Meer, J. W., Eijsvogels, T. M., et al. (2016). The impact of central and peripheral cyclooxygenase enzyme inhibition on exercise-induced core body temperature elevations. Int. J. Sports Physiol. Perform. 12, 662-667. doi: 10.1123/ijspp.2016-0382

Vitols, S. (2003). Paracetamol hepatotoxicity at therapeutic doses. J. Intern. Med. 253, 95-98. doi: 10.1046/j.1365-2796.2003.01107.x

Warden, S. J. (2010). Prophylactic use of NSAIDs by athletes: a risk/benefit assessment. Phys. Sportsmed. 38, 132-138. doi: 10.3810/psm.2010.04.1770

Yeh, Y. J., Law, L. Y. L., and Lim, C. L. (2013). Gastrointestinal response and endotoxemia during intense exercise in hot and cool environments. Eur. J. Appl. Physiol. 113, 1575-1583. doi: 10.1007/s00421-013-2587-x

Yoon, E., Babar, A., Choudhary, M., Kutner, M., and Pyrsopoulos, N. (2016). Acetaminophen-induced hepatotoxicity: a comprehensive update. J. Clin. Transl. Hepatol. 4, 131-142. doi: 10.14218/JCTH.2015.00052

Zimmerman, H. J., and Maddrey, W. C. (1995). Acetaminophen (paracetamol) hepatotoxicity with regular intake of alcohol: analysis of instances of therapeutic misadventure. Hepatology 22, 767-773. doi: $10.1002 /$ hep. 1840220312

Conflict of Interest Statement: The authors declare that the research was conducted in the absence of any commercial or financial relationships that could be construed as a potential conflict of interest.

Copyright (C) 2017 Esh, Mauger, Palfreeman, Al-Janubi and Taylor. This is an openaccess article distributed under the terms of the Creative Commons Attribution License (CC BY). The use, distribution or reproduction in other forums is permitted, provided the original author(s) or licensor are credited and that the original publication in this journal is cited, in accordance with accepted academic practice. No use, distribution or reproduction is permitted which does not comply with these terms. 